\title{
Infliximab as Alternative Therapy in Renal AA Amyloidosis Secondary to Rheumatoid Arthritis
}

\author{
Sahli $\mathbf{H}^{1,2 *}$, Bachali $\mathrm{A}^{1,3}$, Tekaya $\mathbf{R}^{1,4}$, Amri R ${ }^{1,2}$, \\ Boussaadia I ${ }^{1,5}$ and Ouali J ${ }^{1,5}$ \\ ${ }^{1}$ Medicine Faculty of Tunis, University of Tunis El Manar, \\ Tunisia \\ ${ }^{2}$ Department of Internal Medicine, University of \\ Mohamed Taher hospital, Tunisia \\ ${ }^{3}$ Department of Biochemistry, University of Mohamed \\ Taher hospital, Tunisia \\ ${ }^{4}$ Department of Rheumatology, Charles Nicolle hospital, \\ Tunisia \\ ${ }^{5}$ Department of Nephrology, University of Mohamed \\ Taher hospital, Tunisia \\ *Corresponding author: Sahli H, Professor in \\ Rheumatology, Medicine Faculty of Tunis, University of \\ Tunis El Manar Maamouri Hospital, Nabeul, Tunisia
}

Received: October 09, 2017; Accepted: October 31, 2017; Published: November 15, 2017

\section{Introduction}

AA Amyloidosis is a rare complication of rheumatoid arthritis (RA) [1] which has a poor prognosis and a difficult and uncodified treatment [2]. The use of anti-tumor necrosis factor (TNF) alpha may be an interesting alternative in patients with amyloidosis secondary to RA.

We report here the case of a patient who presented renal amyloidosis relevant to RA and treated effectively with infliximab.

\section{Case Presentation}

In October 2015, a 44-year-old woman with no medical history was admitted for generalized edema of unknown etiology. She reported pain and swelling of small joints of hands for two years. His physical exam revealed polyarthritis of large and small joints with no deformities in addition to the presence of edema. The diagnosis of RA was done according to the 2010 rheumatoid arthritis criteria [3]. The patient was positive for rheumatoid factor and for citrullinated anti-peptide antibodies and she had no erosion on radiographs. The disease was active with disease activity score (DAS28) about 8.17 and associated with considerable functional discomfort. A nephrotic syndrome was confirmed with the presence of proteinemia (49.8 $\mathrm{g} / \mathrm{l})$, albuminemia $(15.7 \mathrm{~g} / \mathrm{l})$ and proteinuria (3.3 g per day). Renal biopsy confirmed the presence of AA Amyloidosis responsible for the nephrotic syndrome. No clinical signs of amyloid involvement in the others organs were observed. The renal function was normal. She was prescribed $10 \mathrm{mg}$ of prednisone per day and $10 \mathrm{mg}$ of methotrexate per week. After 6 months of treatment, the patient was admitted for worsening of proteinuria at $6.15 \mathrm{~g} / 24$ hours. The decision in a multidisciplinary consultation meeting with nephrologists was to prescribe infliximab at $3 \mathrm{mg} / \mathrm{kg} / \mathrm{cure}$ at week 0 , week 6 , week 8 and then every 8 weeks, corticosteroids and proteinuria with nephroprotective therapy. She has received nine cures to date. The amount of proteinuria decreased to 2.04 /day and serum albumin level gradually recovered from $15.7 \mathrm{~g} / \mathrm{l}$ to $28.8 \mathrm{~g} / \mathrm{l}$. Edema was reduced and localized to the lower limbs. There were no adverse effects or impairment of renal function. Regarding RA, clinical remission was obtained from the fourth cure.

\section{Discussion}

We reported here a rare case of AA amyloidosis relevant to RA in a 44-year-old woman who responded quickly and favorably to an antiTNF alpha agent "infliximab" with good tolerability. The use of an antiTNF alpha agent in AA amyloidosis is provided from the cytokine role in the pathogenesis of AA amyloidosis. It has been shown that TNF induces amyloid production in the hepatocyte during the acute phase of the inflammatory response [4], stimulates fibrillogenesis in vivo [5] and the production of non-specific receptors that will capture the amyloid fibrils, allowing their accumulation and consequently the cell death [6]. The blocking of TNF by the anti-TNF agents will then make it possible to reduce the activity of the inflammatory disease and thus the synthesis of AA protein. In 2003, Gottenberg, et al. [7] reported 15 cases of secondary AA amyloidosis among them five RA. Three were treated with infliximab and two with etanercept. A decrease in proteinuria was noted in 2 cases (one case of infliximab and one case of etanercept). However, impaired renal function was noted in all 5 cases. Several other cases reported in the literature have shown a rapid decrease in proteinuria without increasing serum creatinine level as noted in our observation [8-10]. TNF alpha antagonists have been used in combination with disease-modifying antirheumatic drugs as in this case. The responses are always evaluated in the short term and relates mainly to markers of kidney damage, proteinuria and renal insufficiency. In a larger series [11], 25 patients (16 RA, 5 ankylosing spondylitis and 4 psoriatic arthritis) were treated with infliximab $(22$ patients) or etanercept (3 patients). After an average of 70 weeks, a decrease in proteinuria was observed in almost all patients and a 
decrease or stabilization of plasma creatinine level in $83 \%$ of cases. In this series, the improvement of proteinuria was simultaneous to the improvement of inflammatory disease but the anti TNF appear little effective on the renal impairment already installed. There are recent retrospective studies of the efficacy of biotherapies during secondary amyloidosis like that of Kuroda, et al. published in 2012 [12]. In this study, including 53 RA with AA amyloidosis treated by biotherapy mainly anti-TNF alpha in first intention, there was a decrease in mortality in these patients compared to patients who were not under biotherapy but without reduction of the risk of the evolution towards hemodialysis. In another retrospective German multicenter study [13], 30 cases of amyloidosis secondary to RA treated with biologic agents were reported ( 23 were treated by anti-TNF TNF-blocking agents). Proteinuria values decreased by $25 \%$ in 13 of 23 patients and remained stable in 5 patients. Creatinine values increased in only 2 patients. The authors used a composite score to evaluate the renal response and noted a positive response in $52.2 \%$ of patients.

\section{Conclusion}

Anti-TNF alpha was well-tolerated and safe in the treatment of renal amyloidosis secondary to RA. This treatment could be an interesting therapeutic alternative for a complication with a severe prognosis and a poor therapeutic arsenal.

\section{References}

1. Cantagrel A, Pourrat J, Fournié B. L'atteinte rénale au cours de la polyarthrite rhumatoïde. Rev Rhum 1990; 57: 303-307.

2. Kuroda T, Tanabe N, Harada T, Murakami S, Hasegawa H, Sakatsume $\mathrm{M}$, et al. Long term mortality outcome in patients with reactive amyloidosis associated with rheumatoid arthritis. Clin Rheumatol. 2006; 25: 498-505.

3. Aletaha D, Neogi T, Silman AJ, Funovits J, Felson DT, Bingham CO 3rd et al. 2010 Rheumatoid arthritis classification criteria: an American College of Rheumatology/European League Against Rheumatism collaborative initiative. Ann Rheum Dis. 2010; 69: 1580-1588.
4. Urieli-Shoval S, Linke RP, Matzner Y. Expression and function of serum amyloid $A$, a major acute-phase protein, in normal and disease states. Curr Opin Hematol. 2000; 7: 64-69.

5. Niewold TA, Gruys E, Kisilevsky R, Shirahama TS. Fibril amyloid enhancing factor (FAEF)-accelerated amyloidosis in the hamster is not dependent on serine esterase activity and mononuclear phagocytosis. Scand J Immunol. 1991; 34: 101-107.

6. Yan SD, Zhu H, Zhu A, Golabek A, Du H, Roher A, et al. Receptor-dependent cell stress and amyloid accumulation in systemic amyloidosis. Nat Med. 2000; 6: 643-651.

7. Gottenberg JE, Merle-Vincent F, Bentaberry F, Allanore Y, Berenbaum F, Fautrel B, et al. CCC. Arthritis Rheum. 2003; 48: 2019-2024.

8. Elkayam O, Hawkins PN, Lachmann H, Yaron M, Caspi D. Rapid and complete resolution of proteinuria due to renal amyloidosis in a patient with rheumatoid arthritis treated with infliximab. Arthritis Rheum. 2002; 46: 2571 2573.

9. Smith GR, Tymms KE, Falk M. Etanercept treatment of renal amyloidosis complicating rheumatoid arthritis. Intern Med J. 2004; 34: 570-572.

10. Nobre CA, Monteiro Callado MR, Maia Rodrigues CE, de Menezes DB, Vieira WP. Anti-TNF therapy in renal amyloidosis in refractory rheumatoid arthritis: a new therapeutic perspective. Bras J Rheumatol. 2010; 50: 205-210.

11. Fernandez-Nebro A, Tomero E, Ortiz-Santamaria V, Castro MC, Olivé A, de Haro $M$, et al. Treatment of rheumatic inflammatory disease in 25 patients with secondary amyloidosis using tumor necrosis factor alpha antagonists. Am J Med. 2005; 118: 552-556.

12. Kuroda T, Tanabe N, Kobayshi D, Sato H, Wada Y, Murakami S, et al. Treatment with Biologic Agents Improves the Prognosis of Patients with Rheumatoid Arthritis and Amyloidosis. J Rheumatol. 2012; 39: 1348-1354.

13. Pamuk ÖN, Kalyoncu U, Aksu K, Omma A, Pehlivan Y, Çağatay Y, et al. A multicenter report of biologic agents for the treatment of secondary amyloidosis in Turkish rheumatoid arthritis and ankylosing spondylitis patients. Rheumatol Int. 2016; 36: 945-953.
Austin J Nephrol Hypertens - Volume 4 Issue 3 - 2017 ISSN : 2381-8964 | www.austinpublishing group.com Sahli et al. () All rights are reserved
Citation: Sahli H, Bachali A, Tekaya R, Amri R, Boussaadia I and Ouali J. Infliximab as Alternative Therapy in Renal AA Amyloidosis Secondary to Rheumatoid Arthritis. Austin J Nephrol Hypertens. 2017; 4(3): 1074. 